\title{
A vibrational spectroscopic study of the arsenate minerals cobaltkoritnigite and koritnigite
}

\author{
Ray L. Frost ${ }^{\mathrm{a}, *}$, Andrés López ${ }^{\mathrm{a}}$, Yunfei Xi ${ }^{\mathrm{a}}$, Cristiano Lana ${ }^{\mathrm{b}}$, Larissa Souza ${ }^{\mathrm{c}}$, Ricardo Scholz ${ }^{\mathrm{b}}$, Jiří Sejkora ${ }^{\mathrm{d}}$, \\ Jiří Čejka ${ }^{\mathrm{a}, \mathrm{d}}$

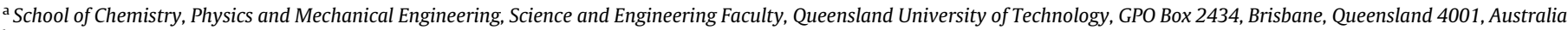 \\ ${ }^{\mathrm{b}}$ Geology Department, School of Mines, Federal University of Ouro Preto, Campus Morro do Cruzeiro, Ouro Preto, MG 35400-00, Brazil \\ ${ }^{c}$ Mining Engineering Department, School of Mines, Federal University of Ouro Preto, Campus Morro do Cruzeiro, Ouro Preto, MG 35400-00, Brazil \\ ${ }^{\mathrm{d}}$ Department of Mineralogy and Petrology, National Museum, Cirkusová 1740, CZ-193 00, Praha 9, Czech Republic
}

\section{H I G H L I G H T S}

- Raman and infrared spectra of cobaltkoritnigite were obtained and interpreted.

- A comparison is made with koritnigite.

- Some phosphate substitution is observed.

- Raman bands were attributed to the $\left(\mathrm{AsO}_{3} \mathrm{OH}\right)^{2-}$ stretching and bending vibrations.
G R A P H I C A L A B S T R A C T

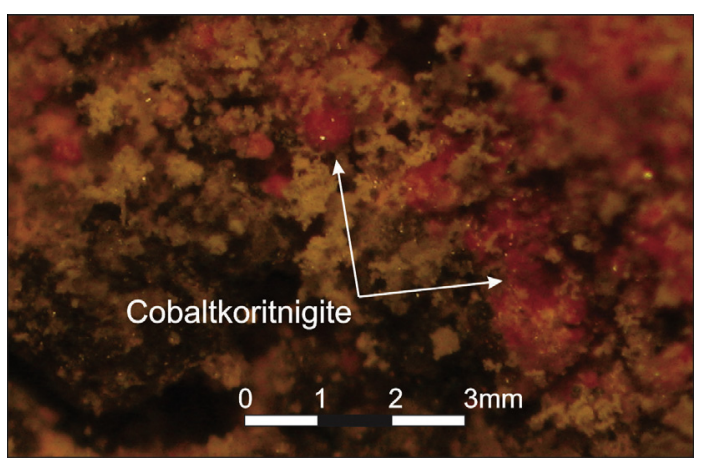

A B S T R A C T

Raman spectra of two well-defined types of cobaltkoritnigite and koritnigite crystals were recorded and interpreted. Significant differences in the Raman spectra of cobaltkoritnigite and koritnigite were observed. Observed Raman bands were attributed to the $\left(\mathrm{AsO}_{3} \mathrm{OH}\right)^{2-}$ stretching and bending vibrations, stretching and bending vibrations of water molecules and hydroxyl ions. Both Raman and infrared spectra of cobaltkoritnigite identify bands which are attributable to phosphate and hydrogen phosphate anions proving some substitution of phosphate for arsenate in the structure of cobaltkoritnigite. The $\mathrm{O}-\mathrm{H} \cdots \mathrm{O}$ hydrogen bond lengths in the crystal structure of koritnigite were inferred from the Raman spectra and compared with those derived from the X-ray single crystal refinement. The presence of $\mathrm{AsO}_{3-}$ $\mathrm{OH})^{2-}$ units in the crystal structure of cobaltkoritnigite and koritnigite was proved from the Raman spectra which supports the conclusions of the X-ray structure analysis.

() 2014 Elsevier B.V. All rights reserved.

\section{Introduction}

Cobaltkoritnigite is the Co member of the koritnigite group that also includes magnesiokoritnigite, the Mg member. Cobaltkoritnigite was first described from Schwarzenberg District, Saxony, Ger-

\footnotetext{
* Corresponding author. Tel.: +61 73138 2407; fax: +61 731381804 .

E-mail address: r.frost@qut.edu.au (R.L. Frost).
}

many [1]. The mineral crystallizes with triclinic symmetry, space group $P-1$, unit cell paramethers $a=7.95 \AA, b=15.83 \AA$, $c=6.67 \AA$, $\alpha=90.9^{\circ}, \beta=96.6^{\circ}, \gamma=90.0^{\circ}$. Despite the type locality, a number of occurrences are reported in the literature [2-4]. A recent study of the structure of the mineral koritnigite has been published [5]. In this work we make a comparison between the Raman spectra of cobaltkoritnigite and koritnigite and an assessment of their molecular structures. 
The Raman spectra of the tetrahedral anions in aqueous systems are well known. The symmetric stretching vibration of the arsenate anion $\left(v_{1}\right)$ is observed at $810 \mathrm{~cm}^{-1}$ and coincides with the position of the asymmetric stretching mode $\left(v_{3}\right)$ [6-8]. The symmetric bending mode $\left(v_{2}\right)$ is observed at $342 \mathrm{~cm}^{-1}$ and the out-of-plane bending modes $\left(v_{4}\right)$ is observed at $398 \mathrm{~cm}^{-1}$. Of all the tetrahedral oxyanions spectra, the positions of the arsenate vibrations occur at lower wavenumbers than any of the other naturally occurring mineral oxyanions spectra. Farmer lists a number of spectra of arsenates including the basic copper arsenates olivenite and euchroite [9]. The effect of the arsenate ion in a crystal will be to remove the degeneracy and allow splitting of the bands according to factor group analysis. The $v_{1}$ and $v_{3}$ bands of olivenite and euchroite were observed at $860,828,790 \mathrm{~cm}^{-1}$ and 830 and $770 \mathrm{~cm}^{-1}$ respectively. The bending modes were found at 493 and $452 \mathrm{~cm}^{-1}$ for olivenite and at 475 and $410 \mathrm{~cm}^{-1}$ for euchroite.

Complex solution chemistry involving mixtures of the cations of lead, zinc, and ferric iron results in the formation of the koritnigite group of minerals, including cobaltkoritnigite. The type of mineral formed is a function of concentration, $\mathrm{pH}$, temperature and the available anion present in the mother solution. The complex set of variable requires a multidimensional phase diagram [10]. Raman spectroscopy has proven an excellent technique for the study of oxyanions in both solution and in secondary mineral formation. In this work we extend our studies to the arsenates of the koritnigite mineral group. The aim of this paper is to report the Raman spectra of cobaltkoritnigite, and to relate the spectra to the molecular structure of this hydrogen-arsenate mineral. A comparison is made with the spectra of koritnigite. The paper follows the systematic research of the large group of supergene minerals and especially molecular structure of minerals containing oxyanions using IR and Raman spectroscopy.

\section{Experimental}

\section{Samples description and preparation}

The cobaltkoritnigite sample studied in this work forms part of the collection of the Geology Department of the Federal University of Ouro Preto, Minas Gerais, Brazil, with sample code SAC-120. The sample is from Richelsdorf District, Hessen, Germany and occurs as spheric to radiating aggregates up to $1 \mathrm{~mm}$. The studied sample of the mineral koritnigite was found in the Jáchymov ore district, the Krušné hory Mountains, Western Bohemia, Czech Republic and is characterized by strawberry pink to pale purple individual crystals formed radiating aggregates up to $1 \mathrm{~mm}$ across. Details of the chemical analysis of this mineral have been published [5].

The sample was gently crushed and the associated minerals were removed under a stereomicroscope Leica MZ4. Scanning electron microscopy (SEM) in the EDS mode was applied to support the mineral characterization.

\section{Scanning electron microscopy (SEM)}

Experiments and analyses involving electron microscopy were performed in the Center of Microscopy of the Universidade Federal de Minas Gerais, Belo Horizonte, Minas Gerais, Brazil (http:// www.microscopia.ufmg.br). Cobaltkoritnigite crystals were analysed with $5 \mu \mathrm{m}$ coating of carbon. Secondary Electron and Backscattering Electron images were obtained using a JEOL JSM6360LV equipment. Qualitative and semi-quantitative chemical analyses in the EDS mode were performed with a ThermoNORAN spectrometer model Quest and were applied to support the mineral characterization.

\section{Raman microprobe spectroscopy}

Crystals of cobaltkoritnigite or koritnigite were placed on a polished metal surface on the stage of an Olympus BHSM microscope, which is equipped with $10 \times, 20 \times$, and $50 \times$ objectives. The microscope is part of a Renishaw 1000 Raman microscope system, which also includes a monochromator, a filter system and a CCD detector (1024 pixels). The Raman spectra were excited by a Spectra-Physics model $127 \mathrm{He}-\mathrm{Ne}$ laser producing highly polarised light at $633 \mathrm{~nm}$ and collected at a nominal resolution of $2 \mathrm{~cm}^{-1}$ and a precision of $\pm 1 \mathrm{~cm}^{-1}$ in the range between 200 and $4000 \mathrm{~cm}^{-1}$. Repeated acquisitions on the crystals using the highest magnification $(50 \times)$ were accumulated to improve the signal to noise ratio of the spectra. Raman spectra were calibrated using the $520.5 \mathrm{~cm}^{-1}$ line of a silicon wafer.

\section{Infrared spectroscopy}

Infrared spectra were obtained using a Nicolet Nexus 870 FTIR spectrometer with a smart endurance single bounce diamond ATR cell. Spectra over the $4000-525 \mathrm{~cm}^{-1}$ range were obtained by the co-addition of 128 scans with a resolution of $4 \mathrm{~cm}^{-1}$ and a mirror velocity of $0.6329 \mathrm{~cm} / \mathrm{s}$. Spectra were co-added to improve the signal to noise ratio.

Spectral manipulation such as baseline correction/adjustment and smoothing were performed using the Spectracalc software package GRAMS (Galactic Industries Corporation, NH, USA). Band component analysis was undertaken using the Jandel 'Peakfit' software package that enabled the type of fitting function to be selected and allows specific parameters to be fixed or varied accordingly. Band fitting was done using a Lorentzian-Gaussian cross-product function with the minimum number of component bands used for the fitting process. The Gaussian-Lorentzian ratio was maintained at values greater than 0.7 and fitting was undertaken until reproducible results were obtained with squared correlations of $r^{2}$ greater than 0.995 .

\section{Results and discussion}

\section{Chemical characterization}

The BSI image of cobaltkoritnigite sample studied in this work is shown in Fig. S1. The image shows a $50 \mu \mathrm{m}$ aggregate of platy crystals. Fragments up to $2 \mu \mathrm{m}$ of an unidentified $\mathrm{Al}$ sulphate occur in association. Qualitative and semi-quantitative chemical composition shows a Co arsenate with minor amounts of Al. The chemical analysis is reported in Fig. S2.

\section{Vibrational spectroscopy background}

The basis of the interpretation of the spectra of both Raman and infrared spectroscopy are given in detail in Ref. [5] and is in part repeated here. Farmer [9] presented and interpreted the mainly infrared spectra of many arsenate minerals (chapter 17). In this chapter discussion of the vibrational spectra of phosphates and arsenates is provided. The spectra of koritnigite and cobaltkoritnigite was not found. According to Myneni et al. [11,12] and Nakamoto [13], $\left(\mathrm{AsO}_{4}\right)^{3-}$ is a tetrahedral unit, which exhibits four fundamental vibrations: the Raman active $v_{1}$ symmetric stretching vibration $\left(A_{1}\right)$ at $818 \mathrm{~cm}^{-1}$; the Raman active doubly degenerate $v_{2}$ symmetric bending vibration $(E)$ observed at $350 \mathrm{~cm}^{-1}$, the infrared and Raman active triply degenerate $v_{3}$ antisymmetric stretching vibration $\left(F_{2}\right)$ found around $786 \mathrm{~cm}^{-1}$, and the infrared and Raman active triply degenerate $v_{4}$ bending vibration $\left(F_{2}\right)$ observed at $405 \mathrm{~cm}^{-1}$. Protonation, metal complexation, and/or adsorption 
on a mineral surface will cause the change in $\left(\mathrm{AsO}_{4}\right)^{3-}$ symmetry from $T_{d}$ to lower symmetries, such as $C_{3 v}, C_{2 v}$ or even $C_{1}$. This loss of degeneracy causes splitting of degenerate vibrations of $\mathrm{AsO}_{4}^{3-}$ and the shifting of the As- $\mathrm{OH}$ stretching vibrations to different wavenumbers. Such information is not given in Farmer's treatise [9]. These fundamentals of the spectra of the arsenate anion are used to interpret the Raman and infrared spectra of cobaltkoritnigite.

Such chemical interactions reduce $\mathrm{AsO}_{4}^{3-}$ tetrahedral symmetry, as mentioned above, to either $C_{3 v} / C_{3}$ (corner-sharing), $C_{2 v} / C_{2}$ (edge-sharing, bidentate binuclear), or $C_{1} / C_{s}$ (corner-sharing, edge-sharing, bidentate binuclear, multidentate) $[11,12]$. In association with $\mathrm{AsO}_{4}^{3-}$ symmetry and coordination changes, the $A_{1}$ band may shift to different wavenumbers and the doubly degenerate $E$ and triply degenerate $F$ modes may give rise to several new $A_{1}$, $B_{1}$, and/or $E$ vibrations [11,12]. In the absence of symmetry deviations, $\mathrm{AsO}_{3} \mathrm{OH}^{2-}$ in $\mathrm{C}_{3 \mathrm{v}}$ symmetry exhibit the $\mathrm{v}_{\mathrm{s}} \mathrm{As}-\mathrm{OH}$ and $\mathrm{v}_{\mathrm{as}}$ and $v_{\mathrm{s}} \mathrm{AsO}_{3} \mathrm{OH}^{2-}$ vibrations together with corresponding the $\delta \mathrm{As}-\mathrm{OH}$ in-plane bending vibration, $\delta$ As- $\mathrm{OH}$ out-of-plane bending vibration, $v_{\mathrm{s}} \mathrm{AsO}_{3} \mathrm{OH}^{2-}$ stretching vibration and $\delta_{\mathrm{as}}\left(\mathrm{AsO}_{3} \mathrm{OH}\right)^{2-}$ bending vibration [14-16]. Keller [14] assigned observed the following infrared bands in $\mathrm{Na}_{2}\left(\mathrm{AsO}_{3} \mathrm{OH}\right) \cdot 7 \mathrm{H}_{2} \mathrm{O} 450$ and $360 \mathrm{~cm}^{-1}$ to the $\delta_{\text {as }}$ $\left(v_{4}\right)\left(\mathrm{AsO}_{3} \mathrm{OH}\right)^{2-}$ bend $(E), 580 \mathrm{~cm}^{-1}$ to the $\delta \mathrm{As}-\mathrm{OH}$ out-of-plane bend, $715 \mathrm{~cm}^{-1}$ to the $v$ As- $\mathrm{OH}$ stretch $\left(A_{1}\right), 830 \mathrm{~cm}^{-1}$ to the $v_{\text {as }}$ $\mathrm{AsO}_{3} \mathrm{OH}^{2-}$ stretch $(E)$, and $1165 \mathrm{~cm}^{-1}$ to the $\delta \mathrm{As}-\mathrm{OH}$ in plane bend. In the Raman spectrum of $\mathrm{Na}_{2}\left(\mathrm{AsO}_{3} \mathrm{OH}\right) \cdot 7 \mathrm{H}_{2} \mathrm{O}$, Vansant and Veken [15] attributed observed Raman bands to the following vibrations $55,94,116$ and $155 \mathrm{~cm}^{-1}$ to lattice modes, $210 \mathrm{~cm}^{-1}$ to $v(\mathrm{OH} \cdots \mathrm{O})$ stretch, $315 \mathrm{~cm}^{-1}$ to $\left(\mathrm{AsO}_{3} \mathrm{OH}\right)^{2-}$ rocking, $338 \mathrm{~cm}^{-1}$ to the $\delta_{\mathrm{s}}\left(\mathrm{AsO}_{3}\right)^{2-}$ bend, $381 \mathrm{~cm}^{-1}$ to the $\delta_{\mathrm{as}}\left(\mathrm{AsO}_{3} \mathrm{OH}\right)^{2-}$ bend, $737 \mathrm{~cm}^{-1}$ to the $v_{\mathrm{s}}$ As- $\mathrm{OH}$ stretch $\left(\mathrm{A}_{1}\right), 866 \mathrm{~cm}^{-1}$ to the $\mathrm{v}_{\text {as }}\left(\mathrm{AsO}_{3-}\right.$ $\mathrm{OH})^{2-}$ stretch $(E)$. The elucidation of these bands is of importance for the study of the arsenate containing minerals and especially those minerals containing hydrogen arsenate anions.

\section{Vibrational spectroscopy}

The Raman spectrum of cobaltkoritnigite and koritnigite in the $100-4000 \mathrm{~cm}^{-1}$ spectral range are illustrated in Fig. $1 \mathrm{a}$ and $\mathrm{b}$. These spectra show the position of the Raman bands and their relative intensities. It is obvious that there are large parts of the spectrum where little or no intensity is observed. Therefore, the spectrum is subdivided into sections according to the type of vibration being investigated. In this way, the precise position of the bands can be detailed. The infrared spectrum of cobaltkoritnigite in the $500-4000 \mathrm{~cm}^{-1}$ spectral range is shown in Fig. 1c. The reflectance spectrum starts at $500 \mathrm{~cm}^{-1}$ because the ATR cell absorbs all infrared radiation below this wavenumber. As for the Raman spectrum, the infrared spectrum is subdivided into sections depending upon the type of vibration being examined. The complete infrared spectrum displays the position of the infrared bands and their relative intensity.

The Raman spectrum of cobaltkoritnigite in the $800-1100 \mathrm{~cm}^{-1}$ spectral range is displayed in Fig. 2a. This spectrum is the region where the stretching vibrations of the oxyanions in this case the arsenate and hydroxyarsenate anions are observed. The Raman spectrum of koritnigite in the $800-1100 \mathrm{~cm}^{-1}$ spectral range is displayed in Fig. 4b. This spectrum appears cleaner that for the cobaltkoritnigite.

In the range from 700 to $900 \mathrm{~cm}^{-1}$, a set of Raman bands for cobaltkoritnigite was observed (Fig. 2a) at 812, 828 and $838 \mathrm{~cm}^{-1}$ and may be compared with the data downloaded from the RRUFF data base for koritnigite. RRUFF is the name of the data base for the Raman spectra of minerals held at the Arizona State University. No interpretation of the Raman data is given. However, useful comparisons may be made with the data for the RRUFF data
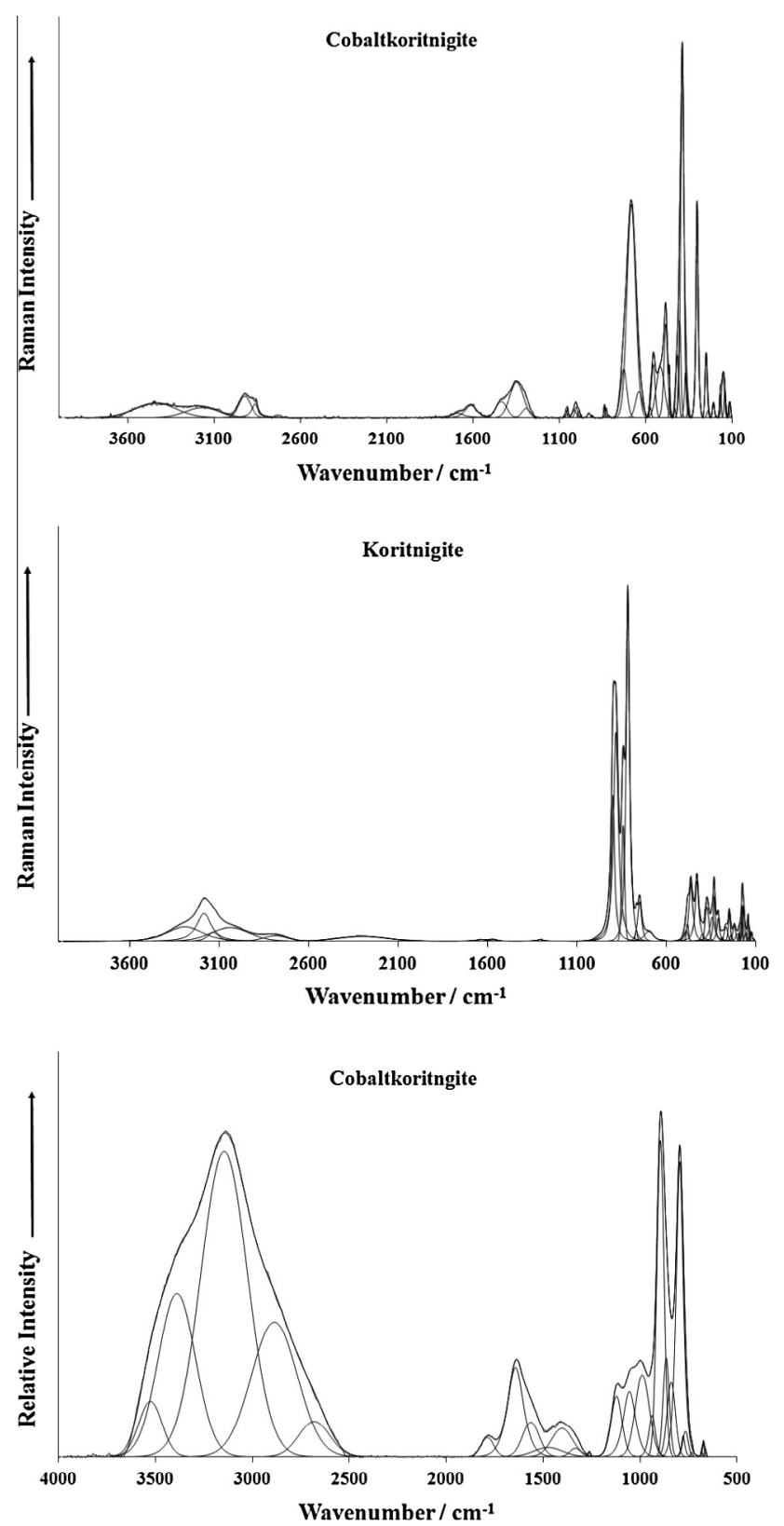

Fig. 1. (a) Raman spectrum of cobaltkoritnigite (upper spectrum) over the 100$4000 \mathrm{~cm}^{-1}$ spectral range, (b) Raman spectrum of koritnigite (middle spectrum) over the $100-4000 \mathrm{~cm}^{-1}$ spectral range and (c) infrared spectrum of cobaltkoritnigite (lower spectrum) over the $500-4000 \mathrm{~cm}^{-1}$ spectral range.

base and the spectra recorded in this work. The Raman spectrum of koritnigite (Fig. 2b) displays bands at $813,839,879$ and $895 \mathrm{~cm}^{-1}$. Raman bands from the RRUFF data base are observed at 766,812 , 841,877 and $891 \mathrm{~cm}^{-1}$ [RRUFF] and infrared bands at 845,815 and $760 \mathrm{~cm}^{-1}$. Respecting intensities of observed bands, the bands close to $813 \mathrm{~cm}^{-1}$ are attributed to the $v_{1}\left(\mathrm{AsO}_{3} \mathrm{OH}\right)^{2-}$ symmetric stretching vibrations, while the bands in the range from 895 to $740 \mathrm{~cm}^{-1}$ are assigned to the split degenerate $\mathrm{v}_{3}\left(\mathrm{AsO}_{3} \mathrm{OH}\right)^{2-}$ antisymmetric stretching vibrations. The intensity of these bands are very low for the cobaltkoritnigite. Raman bands close to $766 \mathrm{~cm}^{-1}$ are connected with the $v$ As- $\mathrm{OH}$ stretching vibrations. In the Raman spectrum of cobaltkoritnigite, a series of Raman bands are observed at 973, 985, 1001 and $1013 \mathrm{~cm}^{-1}$. It is suggested that these bands are due to phosphate and hydrogen phosphate stretching vibrations. Thus, it would appear that some 

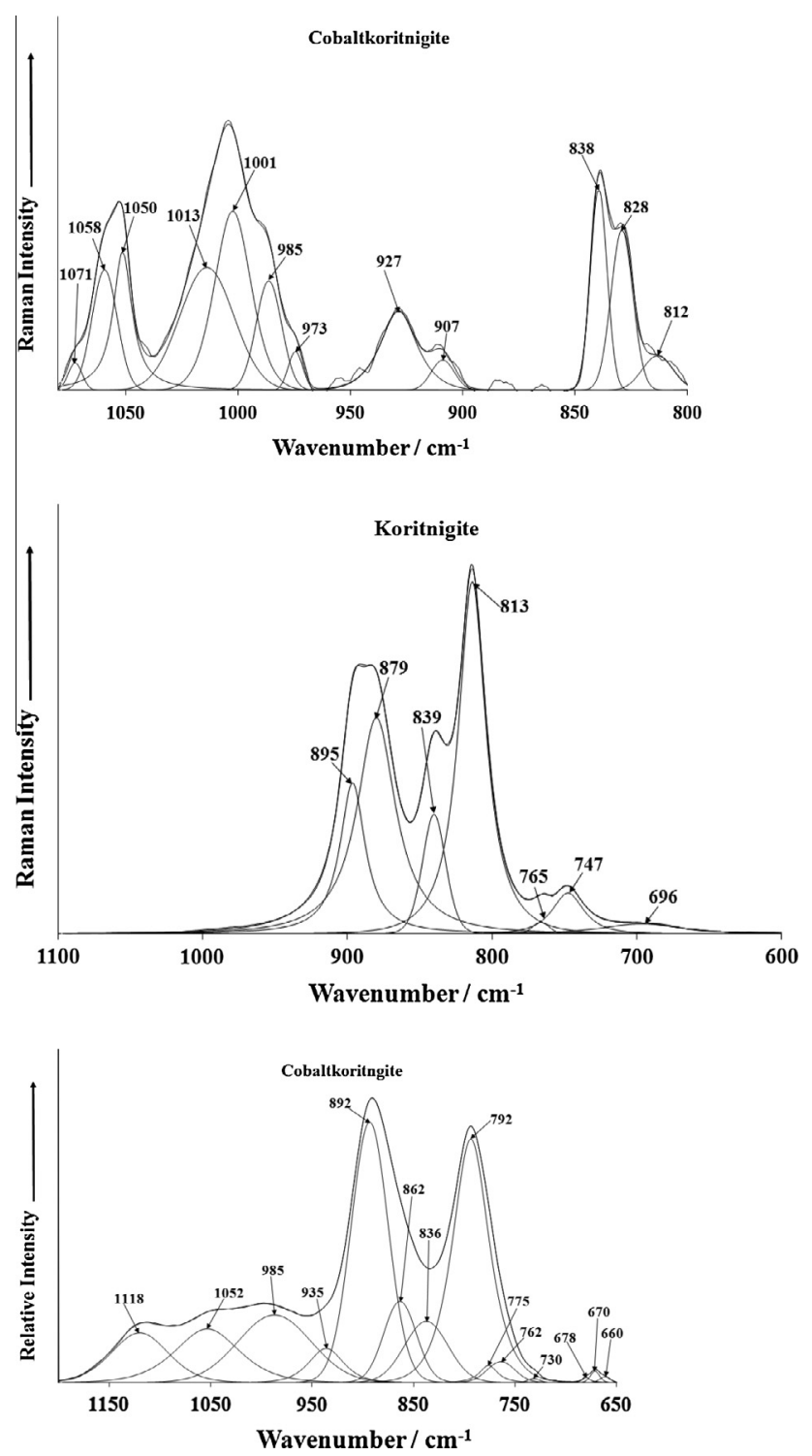

Fig. 2. (a) Raman spectrum of cobaltkoritnigite (upper spectrum) in the 800$1100 \mathrm{~cm}^{-1}$ spectral range, (b) Raman spectrum of koritnigite (middle spectrum) in the $600-1100 \mathrm{~cm}^{-1}$ spectral range and (c) infrared spectrum of cobaltkoritnigite (lower spectrum) in the $650-1200 \mathrm{~cm}^{-1}$ spectral range.

substitution of phosphate for arsenate in the structure of cobaltkoritnigite has occurred. The Raman bands at 1050, 1058 and $1071 \mathrm{~cm}^{-1}$ are ascribed to the $v_{3}$ antisymmetric stretching bands of the phosphate and hydrogen phosphate units.

The infrared spectrum of cobaltkoritnigite in the 650$1200 \mathrm{~cm}^{-1}$ spectral range is shown in Fig. 2c. Intense infrared bands are observed at 792 and $892 \mathrm{~cm}^{-1}$. The infrared band at $892 \mathrm{~cm}^{-1}$ is assigned to the attributed to the $v_{1}\left(\mathrm{AsO}_{3} \mathrm{OH}\right)^{2-}$ symmetric stretching vibration; the band at $792 \mathrm{~cm}^{-1}$ and associated shoulder bands are assigned to the split degenerate $v_{3}\left(\mathrm{AsO}_{3} \mathrm{OH}\right)^{2-}$ antisymmetric stretching vibrations. The infrared bands at 935 and $985 \mathrm{~cm}^{-1}$ are attributed to the $v_{1}\left(\mathrm{PO}_{3} \mathrm{OH}\right)^{2-}$ and $v_{1}\left(\mathrm{PO}_{4}\right)^{3-}$ symmetric stretching vibrations. The broad infrared bands at 1052 and $1118 \mathrm{~cm}^{-1}$ are attributed to the $v_{3}\left(\mathrm{PO}_{3} \mathrm{OH}\right)^{2-}$ and $v_{3}\left(\mathrm{PO}_{4}\right)^{3-}$ antisymmetric stretching vibrations. Clearly, infrared spectroscopy indicates that some substitution of phosphate for arsenate has occurred in the cobaltkoritnigite structure; thus confirming the interpretation of the preceding Raman spectra.

The Raman spectrum of cobaltkoritnigite over the 350$800 \mathrm{~cm}^{-1}$ spectral range is reported in Fig. 3a. The Raman spectrum
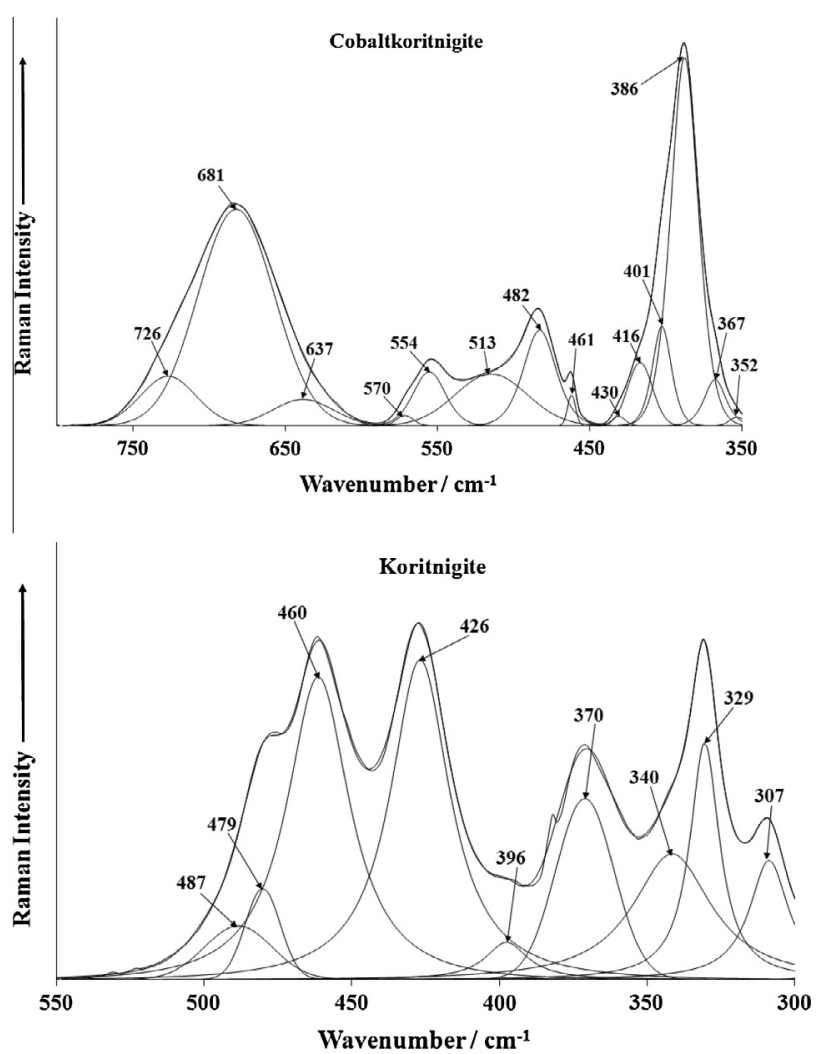

Fig. 3. (a) Raman spectrum of cobaltkoritnigite (upper spectrum) in the 350 $800 \mathrm{~cm}^{-1}$ spectral range and (b) Raman spectrum of koritnigite (lower spectrum) in the $300-550 \mathrm{~cm}^{-1}$ spectral range.
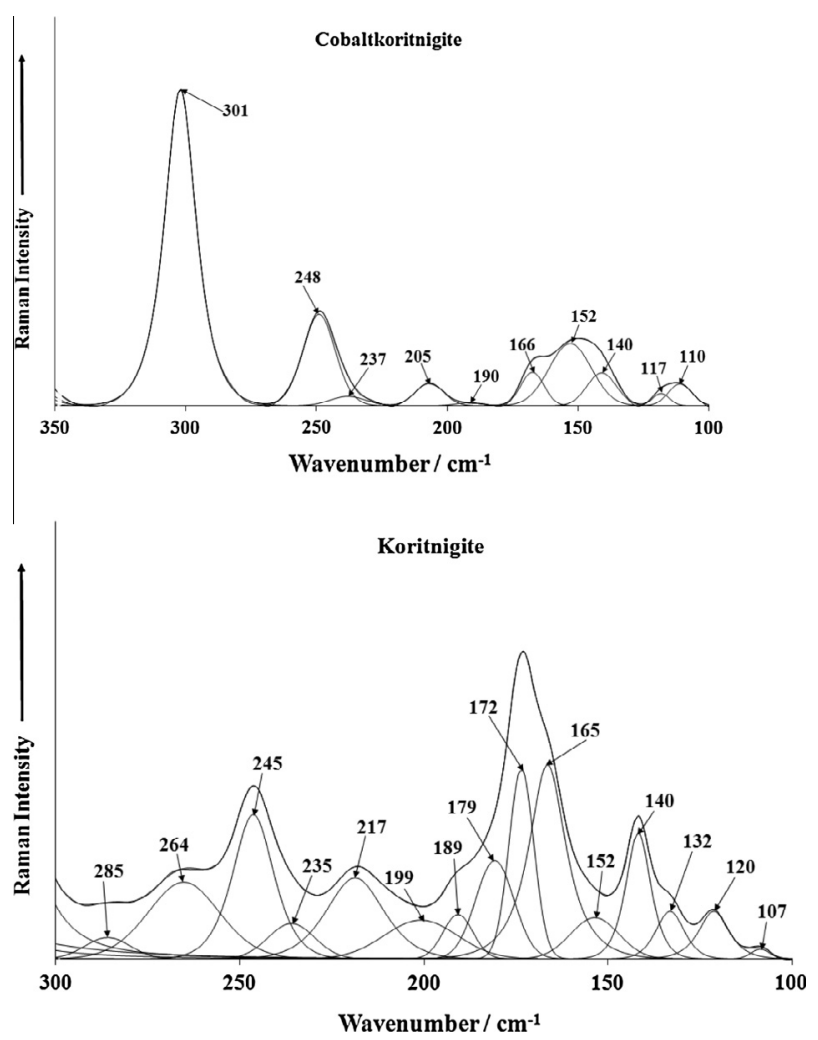

Fig. 4. (a) Raman spectrum of cobaltkoritnigite (upper spectrum) in the 100 $350 \mathrm{~cm}^{-1}$ spectral range and (b) Raman spectrum of koritnigite (lower spectrum) in the $100-300 \mathrm{~cm}^{-1}$ spectral range. 

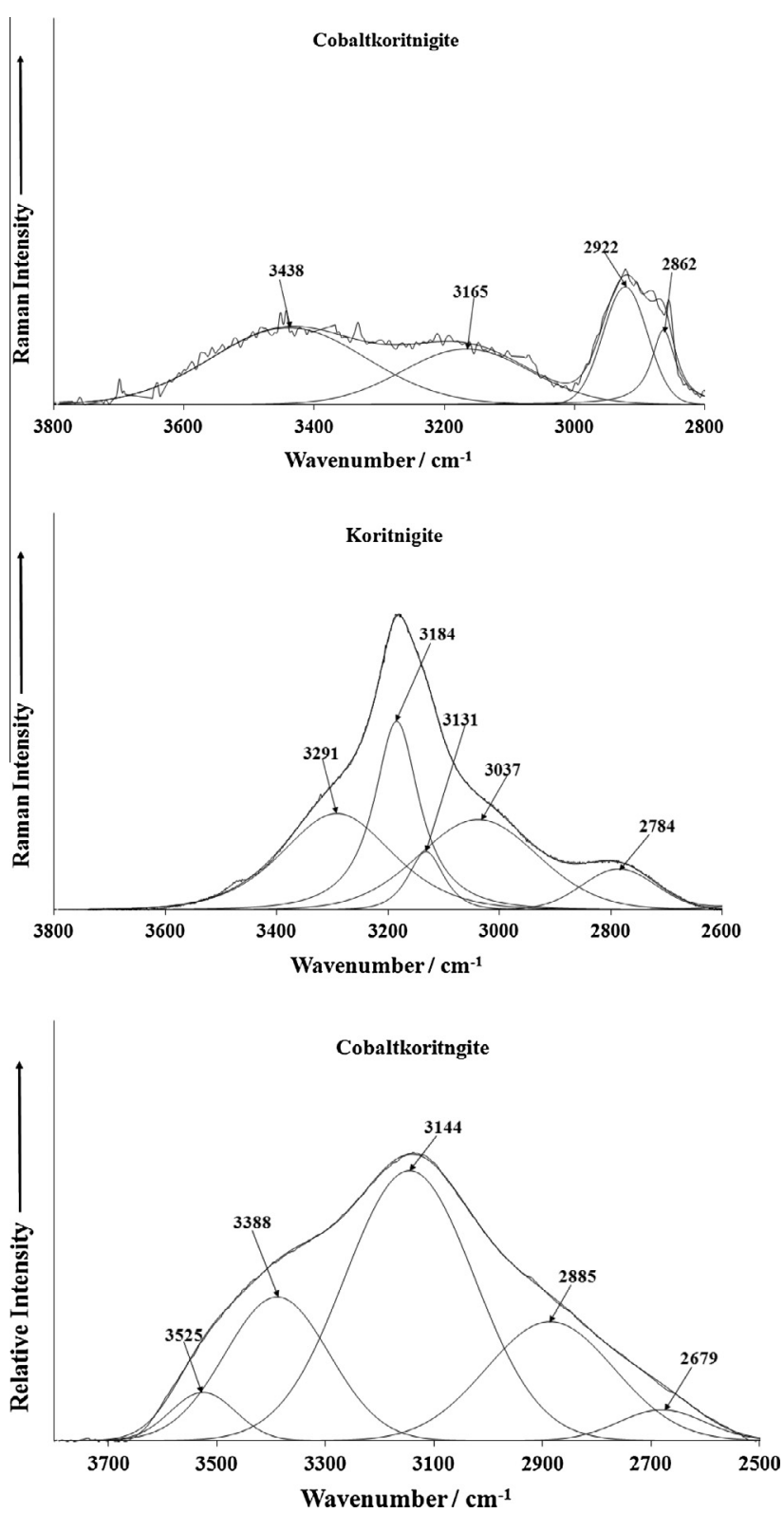

Fig. 5. (a) Raman spectrum of cobaltkoritnigite (upper spectrum) in the 2800$3800 \mathrm{~cm}^{-1}$ spectral range, (b) Raman spectrum of koritnigite (middle spectrum) in the $2800-3800 \mathrm{~cm}^{-1}$ spectral range and (c) infrared spectrum of cobaltkoritnigite (lower spectrum) in the $2500-4000 \mathrm{~cm}^{-1}$ spectral range.

of koritnigite over the $300-550 \mathrm{~cm}^{-1}$ spectral range is reported in Fig. 3b. The Raman bands for cobaltkoritnigite 386, 401, 416, 430, 461 and $482 \mathrm{~cm}^{-1}$ are attributed to the $\mathrm{v}_{4}\left(\mathrm{AsO}_{3} \mathrm{OH}\right)^{2-}$ bending vibrations. Raman bands for koritnigite at 396, 426, 460 and $479 \mathrm{~cm}^{-1}$ and 394,424 and $456 \mathrm{~cm}^{-1}$ (RRUFF) are attributed to the split degenerate $v_{4}\left(\mathrm{AsO}_{3} \mathrm{OH}\right)^{2-}$ bending vibrations and those at 372 and $330 \mathrm{~cm}^{-1}$ and 370 and $327 \mathrm{~cm}^{-1}$ (RRUFF) to the $v_{2}$ $\left(\mathrm{AsO}_{3} \mathrm{OH}\right)^{2-}$ bending vibrations. Keller et al. [17,18] assigned infrared bands at 388 and $378 \mathrm{~cm}^{-1}$ and 350 and $320 \mathrm{~cm}^{-1}$ to these vibrations, respectively. Raman bands at lower wavenumbers such as the band at $300 \mathrm{~cm}^{-1}$ for cobaltkoritnigite may be described as the lattice vibrations (Fig. 4a and b).

The Raman spectrum of cobaltkoritnigite over the 2800$3800 \mathrm{~cm}^{-1}$ spectral range is reported in Fig. 5a. The Raman spectrum of koritnigite over the $2600-3800 \mathrm{~cm}^{-1}$ spectral range is reported in Fig. 5b. Two broad Raman bands for cobaltkoritnigite are observed at 3165 and $3438 \mathrm{~cm}^{-1}$ with two additional bands at 2862 and $2922 \mathrm{~cm}^{-1}$. The first two bands are assigned to water stretching vibrations. The latter two bands are attributed to very strongly hydrogen bonded $\mathrm{OH}$ vibrations. Raman bands for koritnigite at 2784, 3005, 3182 and $3474 \mathrm{~cm}^{-1}$ are assigned to the $v$ $\mathrm{OH}$ stretching vibrations of hydrogen bonded water molecules, while those at 2434 and $2285 \mathrm{~cm}^{-1}$ to the $\mathrm{VOH}$ stretching vibrations of strongly hydrogen bonded $(\mathrm{OH})^{-}$ions in the $\left(\mathrm{AsO}_{3} \mathrm{OH}\right)^{2-}$ units. According to Keller et al. [17,18], infrared bands in the spectrum of cobaltkoritnigite were observed at 3480, 3200, 2770, 2420 and $2280 \mathrm{~cm}^{-1}$ and are close to the Raman spectra studied in this work. The infrared spectrum of cobaltkoritnigite over the 2500$3800 \mathrm{~cm}^{-1}$ spectral range is provided in Fig. 5c. Broad infrared bands are observed at 2679, 2885, 3144, 3388 3525, 3388 and $3525 \mathrm{~cm}^{-1}$. According to Libowitzky, the $\mathrm{O}-\mathrm{H} \ldots \mathrm{O}$ hydrogen bond lengths may vary in the range approximately from 2.80 to $2.73 \AA$. Such hydrogen bond distances are a function of the hydrogen bond strength. The $\mathrm{O}-\mathrm{H} \cdots \mathrm{O}$ hydrogen bond lengths inferred from the
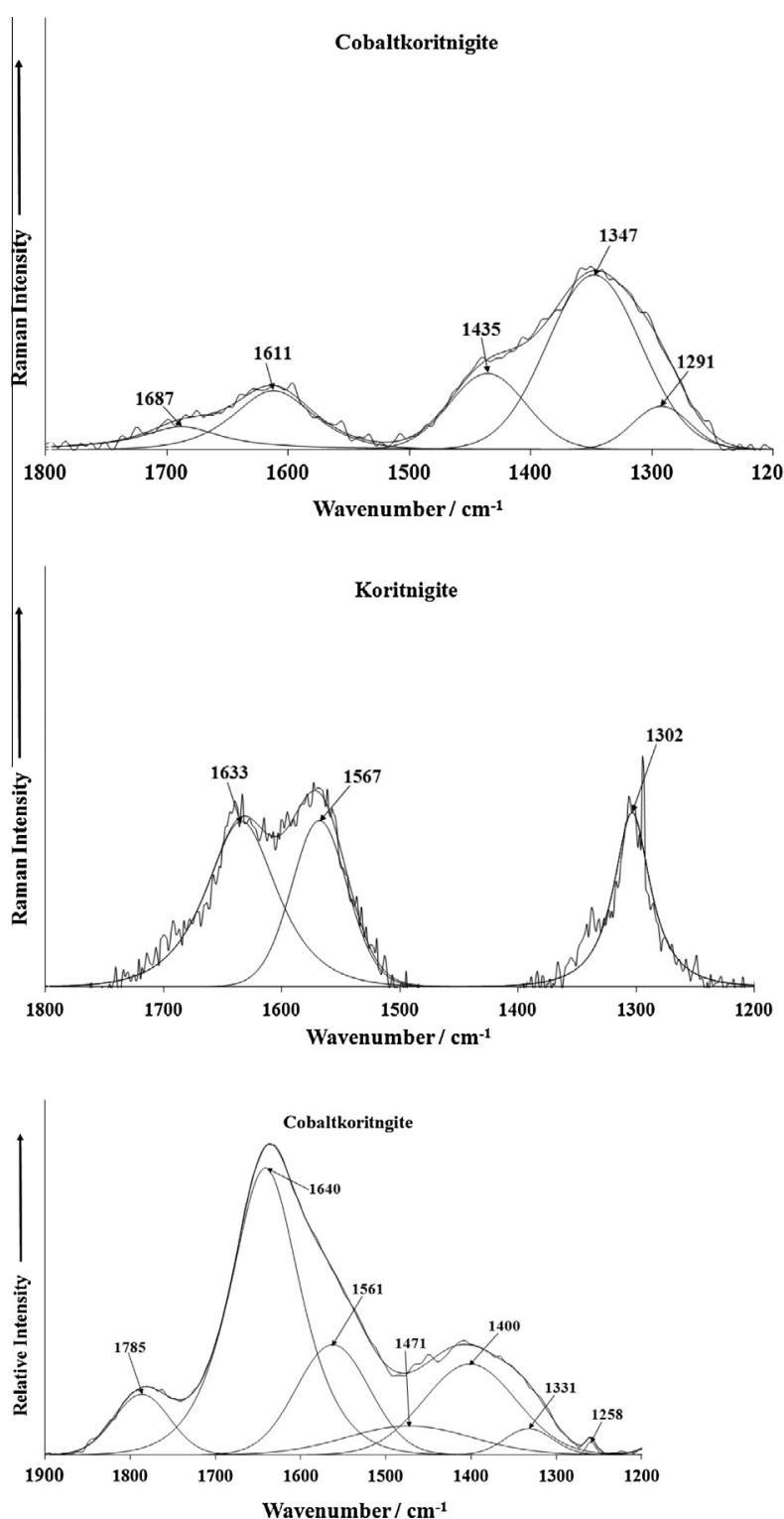

Fig. 6. (a) Raman spectrum of cobaltkoritnigite (upper spectrum) in the 2800$3800 \mathrm{~cm}^{-1}$ spectral range, (b) Raman spectrum of koritnigite (middle spectrum) in the $2800-3800 \mathrm{~cm}^{-1}$ spectral range and (c) infrared spectrum of cobaltkoritnigite (lower spectrum) in the $2500-4000 \mathrm{~cm}^{-1}$ spectral range. 
Raman and infrared spectra of cobaltkoritnigite are located in the range 2.87-2.55 $\AA$ and are comparable with those from the X-ray crystal structure $2.93-2.51 \AA[17,18]$.

The Raman spectrum of cobaltkoritnigite over the 1200$1800 \mathrm{~cm}^{-1}$ spectral range is reported in Fig. 6a. Raman bands are identified at $1291,1347,1435,1611$ and $1687 \mathrm{~cm}^{-1}$. The latter two bands are assigned to the water bending modes of very strongly bonded water and weakly hydrogen bonded water, respectively. The Raman spectrum of koritnigite over the 1200$1800 \mathrm{~cm}^{-1}$ spectral range is reported in Fig. 6b. Raman bands are observed at 1302,1567 and $1633 \mathrm{~cm}^{-1}$. This latter band is ascribed to a water bending mode. The infrared spectrum of cobaltkoritnigite over the $1200-1800 \mathrm{~cm}^{-1}$ spectral range is reported in Fig. 6c. Raman bands at $1567 \mathrm{~cm}^{-1}$ are connected with the $v_{2}(\delta) \mathrm{H}_{2} \mathrm{O}$ bending vibrations. The Raman band at $1302 \mathrm{~cm}^{-1}$ may be probably related to a combination band or overtone. Keller et al. $[17,18]$ attributed infrared bands at 1645 and $1560 \mathrm{~cm}^{-1}$ to these vibrations. Raman bands at $1303 \mathrm{~cm}^{-1}$ are assigned to the $\delta \mathrm{As}-\mathrm{OH}$ bending vibrations, close to $1300 \mathrm{~cm}^{-1}$ observed in the infrared spectrum by Keller et al. [17].

\section{Conclusions}

Raman spectra of two well-defined types of cobaltkoritnigite and koritnigite crystals from Richelsdorf District, Hessen, Germany and Jáchymov ore district, the Krušné Hory Mountains, Western Bohemia, Czech Republic were analysed and related to the structure of the minerals. Substantial differences were observed between the Raman spectra of cobaltkoritnigite and koritnigite. A comparison is made between the Raman spectra of the two minerals. It is noted that cobaltkoritnigite is not as 'clean' as the mineral Czech koritnigite.

The Raman spectra of cobaltkoritnigite and koritnigite are compared, Structural interpretation based upon the Raman spectra is given. Observed Raman bands were attributed to the $\left(\mathrm{AsO}_{3} \mathrm{OH}\right)^{2-}$ stretching and bending vibrations, stretching and bending vibrations of water molecules and hydroxyl ions. The $\mathrm{O}-\mathrm{H} \cdots \mathrm{O}$ hydrogen bond lengths in the crystal structure of cobaltkoritnigite and koritnigite were inferred from the Raman and infrared spectra and compared with those derived from the X-ray single crystal refinement. The presence of $\left(\mathrm{AsO}_{3} \mathrm{OH}\right)^{2-}$ units in the crystal structure of cobaltkoritnigite was proved from the Raman spectra which supports the conclusions of the X-ray structure analysis. Both the Raman and infrared spectra of cobaltkoritnigite identify bands which are assigned to phosphate and hydrogen phosphate bands, supporting the concept that some substitution of phosphate for arsenate in the structure of cobaltkoritnigite occurs.

\section{Acknowledgements}

The financial and infra-structure support of the Discipline of Nanotechnology and Molecular Science, Science and Engineering Faculty of the Queensland University of Technology, is gratefully acknowledged. The Australian Research Council (ARC) is thanked for funding the instrumentation. The authors would like to acknowledge the Center of Microscopy at the Universidade Federal de Minas Gerais (http://www.microscopia.ufmg.br) for providing the equipment and technical support for experiments involving electron microscopy. R. Scholz thanks to CNPq - Conselho Nacional de Desenvolvimento Científico e Tecnológico (Grant No. 306287/ 2012-9). L. Souza thanks to PIBIC/CNPq/UFOP and C. Lana thanks to CNPq 402852/2012-5.

\section{Appendix A. Supplementary material}

Supplementary data associated with this article can be found, in the online version, at http://dx.doi.org/10.1016/j.saa.2014.01.106.

\section{References}

[1] K.W. Schmetzer, O. Horn, Neues Jb. Miner, Mh. (1981) 257-266.

[2] U. Kolitsch, J. Gröbner, G. Blaß, H.-W. Graf, A. Pring, Lapis 30 (2005) 35-39.

[3] G. Favreau, J.E. Dietrich, Die Mineralien von Bou Azzer, Lapis 31 (2006) 27-68.

[4] G. Favreau, J.E. Dietrich, N. Meisser, J. Brugger, L.A. Haddouch, L. Maacha, Min. Rec. 38 (2007) 345-407.

[5] R.L. Frost, J. Sejkora, J. Cejka, J. Plasil, S. Bahfenne, E.C. Keeffe, J. Raman Spectrosc. 42 (2011) 534-539.

[6] W. Martens, R.L. Frost, J.T. Kloprogge, J. Raman Spectrosc. 34 (2003) 90-95.

[7] W. Martens, R.L. Frost, P.A. Williams, J. Raman Spectrosc. 34 (2003) 104-111.

[8] W.N. Martens, R.L. Frost, J.T. Kloprogge, P.A. Williams, Amer. Min. 88 (2003) 501-508.

[9] V.C. Farmer, Mineralogical Society Monograph 4: The Infrared Spectra of Minerals, 1974.

[10] P.A. Williams, Oxide Zone Geochemistry, Ellis Horwood Ltd., Chichester, West Sussex, England, 1990.

[11] S.C.B. Myneni, S.J. Traina, G.A. Waychunas, T.J. Logan, Geochim. Cosmochim. Acta 62 (1998) 3285-3300.

[12] S.C.B. Myneni, S.J. Traina, G.A. Waychunas, T.J. Logan, Geochim. Cosmochim. Acta 62 (1998) 3499-3514.

[13] K. Nakamoto, Infrared and Raman Spectra of Inorganic and Coordination Compounds, Wiley, New York, 1986.

[14] P. Keller, Neues Jb. Miner. Mh. (1971) 491-510.

[15] F.K. Vansant, B.J.V.D. Veken, J. Mol. Struct. 15 (1973) 439-444.

[16] F.K. Vansant, B.J.V.D. Veken, H.O. Desseyn, J. Mol. Struct. (1973) 425-437.

[17] P. Keller, H. Hess, H. Riffel, Neues Jb. Miner. Mh. 138 (1980) 316-332.

[18] P. Keller, H. Hess, P. Suesse, G. Schnorrer, P.J. Dunn, Tsch. Min. Petr. Mitt. 26 (1979) 51-58. 